\title{
Perbedaan pola tanam dan kriteria aplikasi insektisida memengaruhi keanekaragaman arthropoda tanah pada pertanaman kubis (Brassica oleracea)
}

\author{
Different cultivation patterns and insecticide application criteria affect \\ soil arthropod diversity on cabbage cultivation (Brassica oleracea)
}

\author{
Inrianti Sari Handayani $^{{ }^{*}}$, Dadang ${ }^{2}$, Ali Nurmansyah ${ }^{3}$ \\ ${ }^{1}$ Program Studi Entomologi, Departemen Proteksi Tanaman, Fakultas Pertanian, \\ Institut Pertanian Bogor, Jalan Kamper, Kampus IPB Dramaga, Bogor 16680 \\ ${ }^{2}$ Departemen Proteksi Tanaman, Fakultas Pertanian, Institut Pertanian Bogor \\ Jalan Kamper, Kampus IPB Dramaga, Bogor 16680
}

(diterima Juli 2018, disetujui September 2019)

\begin{abstract}
ABSTRAK
Penggunaan pestisida secara berlebihan dan intensif pada tanaman kubis (Brassica oleracea) dapat menyebabkan resistensi, resurgensi, pencemaran lingkungan, residu kimia, dan penurunan populasi musuh alami dan keanekaragaman arthropoda tanah. Berbagai teknik pengendalian hama telah dikembangkan, seperti penggunaan sistem tumpang sari yang merupakan bagian dari teknik budi daya dan juga aplikasi insektisida. Tujuan penelitian ini untuk memelajari efek dari tiga pola tanam kubis dan perbedaan kriteria aplikasi insektisida terhadap keanekaragaman arthropoda tanah. Percobaan disusun berdasarkan rancangan petak terbagi. Tiga pola tanam kubis terdiri atas tumpang sari kubis dan tomat, kubis dan Ageratum sp. sebagai tanaman refugia, dan kubis monokultur. Tiga kriteria dalam aplikasi insektisida, yaitu didasarkan pada ambang ekonomi, aplikasi berjadwal, dan tanpa aplikasi insektisida. Secara umum, pola tanam kubis monokultur dan aplikasi pestisida menyebabkan kelimpahan arthropoda tanah lebih rendah dibandingkan dengan perlakuan lainnya. Perlakuan kubis dengan Ageratum sp. dan tanpa aplikasi insektisida dapat meningkatkan keanekaragaman arthropoda tanah.
\end{abstract}

Kata kunci: Ageratum sp., refugia, tomat, tumpang sari

\begin{abstract}
The use of intensive and excessive insecticides on cabbage cultivations causes pest resistance, pest resurgence, environmental pollution, chemical residues, as well as decreasing the population of natural enemies and soil arthropods. Various pest control techniques have been developed to reduce pest population, two of them are intercropping system as part of cultural technique strategy and insecticide application. The aim of this research was to study the effect of three cabbage (Brassica oleracea) cultivation patterns and different criteria in insecticide application against soil arthropod diversity including natural enemy population. The research was designed using split plot experimental design. The three cultivation patterns consisted of intercropping cabbage with tomato, cabbage and Ageratum sp. as refugia plant, and monoculture cabbage. Three criteria in insecticide application were economic threshold-based application, calendar system, and without insecticide application. In general the results showed that cabbage monoculture cultivation and insecticide application resulted in lowest soil arthropod population among other treatments. Treatments of cabbage and Ageratum sp. and without insecticide application could increase the diversity of soil arthropods.
\end{abstract}

Key words: Ageratum sp., intercropping, refugia, tomato 


\section{PENDAHULUAN}

Kubis (Brassica oleracea) merupakan salah satu tanaman pertanian yang banyak dibutuhkan bagi sebagian besar masyarakat Indonesia. Produksi kubis selain untuk pemenuhan kebutuhan dalam negeri juga merupakan komoditas ekspor yang termasuk kelompok enam besar sayuran komoditi ekspor unggulan Indonesia. Indonesia telah melakukan ekspor kubis ke beberapa negara, seperti Singapura dalam beberapa tahun silam (Arsanti et al. 2017). Beberapa nutrisi penting yang terdapat pada kubis di antaranya vitamin A, B, C, dan E serta mineral penting, seperti kalium, kalsium, fosfor, natrium, dan zat besi (Sastrosiswojo et al. 2005).

Data BPS (2015) menunjukkan bahwa produksi kubis nasional mengalami fluktuasi. Tahun 2011 produksi kubis mencapai 1,35 juta ton dan tahun 2012 dan 2013 mengalami peningkatan produksi berturut-turut menjadi 1,45 juta ton dan 1,47 juta ton, namun pada tahun 2014 produksi menurun menjadi 1,43 juta ton. Beberapa faktor yang mengakibatkan penurunan produksi kubis di antaranya sistem budi daya yang kurang tepat, berkurangnya luas lahan akibat alih fungsi lahan, dan adanya serangan hama dan patogen tanaman.

Kerusakan oleh hama Plutella xylosella L. pada tanaman kubis dapat menurunkan hasil baik kualitas maupun kuantitas. Gejala kerusakannya tampak seperti jendela-jendela putih pada daun yang disebabkan oleh aktivitas makan larva terutama larva instar III. Serangan yang berat dapat mengakibatkan tanaman kubis tidak dapat membentuk krop sehingga menyebabkan gagal panen dan kehilangan hasil mencapai $100 \%$ pada musim kemarau (Setiawati 2015).

Upaya pengendalian, seperti penggunaan tanaman tumpang sari kubis tomat telah banyak diterapkan oleh petani untuk menurunkan populasi hama utama $P$. xylostella, namun umumnya petani masih tetap mengandalkan aplikasi insektisida sebagai tindakan pengendalian utama. Aplikasi insektisida sintetik yang sangat intensif dan berlebihan dapat menimbulkan dampak buruk, seperti resistensi hama, resurjensi hama, terbunuhnya musuh alami, dan masalah pencemaran lingkungan serta penurunan keanekaragaman arthropoda tanah (Subhan et al. 2005).

Dewasa ini telah dilakukan upaya pengendalian hama berbasis ekologi dengan sistem konservasi musuh alami. Menurut Belz et al. (2013) terdapat beberapa upaya konservasi musuh alami untuk meningkatkan aktivitasnya, yaitu dengan memanipulasi lingkungan antara lain menyediakan makanan bagi serangga parasitoid dewasa, seperti nektar yang terdapat pada bunga, menyediakan tempat pengungsian (refugia), dan mempertahankan keberadaan hama dengan populasi rendah diluar musim tanam untuk bertahan hidup musuh alami.

Pemanfaatan tanaman refugia mulai dikembangkan untuk meningkatkan aktivitas musuh alami dan peningkatan kestabilan ekosistem dalam meminimalisir penggunaan insektisida sintetik. Tujuan penelitian ini untuk memelajari pengaruh tiga pola tanam kubis dan perbedaan kriteria aplikasi insektisida terhadap keanekaragaman arthropoda tanah.

\section{BAHAN DAN METODE}

Penelitian dilaksanakan di Kebun Percobaan Pasir Sarongge, Kecamatan Pacet, Kabupaten Cianjur dan Laboratorium Fisiologi dan Toksikologi Serangga, Fakultas Pertanian, Institut Pertanian Bogor yang berlangsung dari bulan Februari hingga Juli 2017.

\section{Persiapan lahan dan penanaman}

Lahan percobaan diolah dan dibuat petakpetak perlakuan. Petak-petak berukuran $7 \mathrm{~m} \mathrm{x} 9 \mathrm{~m}$ sebanyak 9 petak utama digunakan untuk tiap perlakuan utama yang meliputi perlakuan tumpang sari kubis dan tomat, kubis dan tanaman refugia Ageratum sp., dan kubis monokultur. Tanaman Ageratum sp. dan tanaman tomat ditanam dua minggu lebih awal sebelum dilakukan penanaman kubis. Benih kubis varietas Grand 11 dan benih tomat varietas Artaloka digunakan dalam penelitian ini. Pada setiap petak utama dibuat 3 subpetak untuk perlakuan aplikasi insektisida berdasarkan berjadwal (aplikasi insektisida setiap minggu), aplikasi insektisida berdasarkan ambang ekonomi, dan tanpa aplikasi insektisida. Nilai ambang ekonomi untuk $P$. xylostella, yakni 1 larva per 10 tanaman (Helmi et al. 2015). Masingmasing subpetak terdiri atas 40 tanaman kubis dengan jarak tanam $50 \mathrm{~cm}$ x $60 \mathrm{~cm}$ dan jarak antar subpetak $50 \mathrm{~cm}$. Pada setiap subpetak diambil delapan tanaman contoh secara sistematik. 
Pengamatan keanekaragaman dan komposisi arthropoda tanah

Pengamatan arthropoda tanah dilakukan setiap minggu sejak tanaman berumur 5 minggu setelah tanam (MST) hingga satu minggu menjelang panen. Pemasangan 2 perangkap pitfall di setiap petak perlakuan dilakukan 3 hari sebelum pengamatan dilakukan dengan membenamkan perangkap pitfall yang berisi cairan formalin (10\%), dengan lokasi yang telah ditentukan secara sistematis. Arthropoda hasil perangkap pitfall kemudian dibawa ke laboratorium untuk didentifikasi dan dikelompokkan berdasarkan genus dan familinya.

Perhitungan indeks keanekaragaman arthropoda tanah menggunakan rumus ShannonWiener, yaitu

$$
\mathrm{H}^{\prime}=-\sum_{n=1}^{s} p_{i} \ln p_{i} \text {, dengan }
$$

$\mathrm{H}^{\prime}$ : indeks keanekaragaman; $p_{i}$ : kelimpahan proporsional dari jenis ke-I; $p_{i}=\mathrm{Ni} / \mathrm{N}$; Ni: jumlah individu ke-I; N: jumlah individu ke seluruh jenis dalam komunitas.

Nilai indeks:

$<1,5=$ keanekaragaman rendah;

1,5-3,5 = keanekaragaman sedang;

$>3,5=$ keanekaragaman tinggi.

Perhitungan indeks kemerataan dan kekayaan (dominansi) spesies menggunakan rumus Simpson, yaitu

$$
\mathrm{D}=\frac{1}{\sum_{n=1}^{s} p_{i}}, \text { dengan }
$$

$p_{i}$ : proporsi banyaknya spesies $\mathrm{i} ; \mathrm{s}$ : total banyaknya spesies.

Kriteria indeks dominansi Simpson dibagi menjadi 3 kategori (Elhayati et al. 2017), yaitu
Dominansi rendah: D' $=0-0,30$;

Dominansi sedang: D' $=0,31-0,60$;

Dominansi tinggi: $\mathrm{D}^{\prime}=0,61-1,0$.

Serangga yang didapatkan juga dianalisis komposisinya terutama berdasarkan peranannya sebagai predator dan parasitoid untuk masingmasing perlakuan.

\section{Rancangan percobaan dan analisis data}

Percobaan disusun berdasarkan rancangan petak terbagi (split plot design) yang terdiri atas tiga taraf petak utama dan tiga taraf subpetak. Tabel dan grafik diolah dengan menggunakan MS. Office Excel 2010. Data dianalisis dengan ANOVA menggunakan aplikasi SAS 9.1. Nilai tengah pada setiap perlakuan yang berpengaruh nyata diuji lanjut dengan uji SNK pada taraf 5\%.

\section{HASIL}

\section{Keanekaragaman arthropoda tanah}

Indeks keanekargaman pada semua perlakuan baik pada tiga pola tanam maupun perbedaan kriteria dalam aplikasi insektisida berada pada kisaran H' 1,5-3,5 yang tergolong dalam kriteria keanekaragaman sedang (Tabel 1).

Keanekaragaman arthropoda pada 5 MST dan 9 MST terlihat cukup tinggi pada pola tanam kubis + Ageratum sp. dan kubis + tomat dibandingkan dengan kubis monokultur, namun secara umum pola tanam kubis menunjukkan indeks keanekaragaman sedang yang berada pada kisaran H' 1,5-3,5 (Tabel 1).

Keanekaragaman arthropoda berdasarkan kriteria aplikasi insektisida menunjukkan

Tabel 1. Indeks keanekaragaman $(\mathrm{H})$ arthropoda tanah pada pola pertanaman kubis dan kriteria aplikasi insektisida

\begin{tabular}{lccccc}
\hline \multirow{2}{*}{ Perlakuan } & \multicolumn{5}{c}{ Keanekaragaman arthropoda tanah \pm SD pada n-MST } \\
\cline { 2 - 6 } & 5 & 6 & 7 & 8 & 9 \\
\hline \multirow{5}{*}{ Kubis monokultur } & $2,33 \pm 0,91$ & $2,01 \pm 1,20$ & $2,08 \pm 0,96$ & $1,81 \pm 1,04$ & $1,57 \pm 0,88$ \\
Kubis + tomat & $2,63 \pm 1,13$ & $2,42 \pm 0,90$ & $2,07 \pm 1,02$ & $1,87 \pm 0,98$ & $1,84 \pm 0,92$ \\
Kubis + Ageratum sp. & $2,72 \pm 1,02$ & $2,43 \pm 1,18$ & $2,20 \pm 1,33$ & $2,09 \pm 1,37$ & $1,87 \pm 1,10$ \\
& \multicolumn{5}{c}{ Kriteria aplikasi insektisida } \\
Ambang ekonomi & $2,49 \pm 1,41$ & $2,06 \pm 0,83$ & $1,90 \pm 0,77$ & $1,65 \pm 1,82$ & $1,35 \pm 0,39$ \\
Berjadwal & $2,57 \pm 1,22$ & $2,04 \pm 1,30$ & $1,92 \pm 1,48$ & $1,62 \pm 1,30$ & $1,41 \pm 0,55$ \\
Tanpa aplikasi & $2,61 \pm 0,76$ & $2,73 \pm 1,72$ & $2,53 \pm 0,75$ & $2,51 \pm 1,01$ & $2,59 \pm 0,64$ \\
\hline
\end{tabular}

SD: standar deviasi; MST: minggu setlah tanam. 
keanekaragaman arthropoda lebih tinggi pada petak kontrol (tanpa aplikasi insektisida) dibandingkan dengan aplikasi berjadwal dan ambang ekonomi. Penggunaan insektisida menyebabkan penurunan nilai indeks keanekaragaman setiap minggunya dan pada 9 MST menunjukkan nilai indeks keanekaragaman rendah, yakni berada pada kisaran kurang dari H’ 1,5 (Tabel 1).

\section{Dominansi arthropoda tanah}

Berdasarkan hasil analisis menunjukkan nilai indeks dominansi pada 5 MST masih tergolong rendah dengan kategori berkisar $0-0,30$, sedangkan pada 6 MST hingga 9 MST menunjukkan nilai indeks dominansi berada pada kisaran sedang, yakni $0,31-0,60$ dan kategori dominansi tinggi berada pada kisaran 0,61-1,0 (Tabel 2).

\section{Komposisi peranan arthropoda tanah}

Berdasarkan hasil pola pertanaman dan kriteria aplikasi insektisida menunjukkan persentase populasi hama yang diperoleh pada pitfall trap masih lebih rendah dibandingkan dengan populasi predator, sedangkan populasi parasitoid tergolong sangat rendah. Persentase tertinggi musuh alami predator dan parasitoid ditemukan pada petak kubis + Ageratum sp. dengan masing-masing nilai 23,3\% dan 3\% (Tabel 3).

Kriteria aplikasi insektisida menunjukkan persentase populasi predator dan parasitoid lebih tinggi pada petak kontrol (tanpa aplikasi) dibandingkan dengan aplikasi berjadwal dan berdasar ambang ekonomi (Tabel 3). Kinerja musuh alami tersebut dapat terganggu oleh aplikasi insektisida. Aplikasi insektisida memberi

Tabel 2. Indeks dominansi (D) arthropoda tanah pada pola pertanaman kubis dan kriteria aplikasi insektisida

\begin{tabular}{lccccc}
\hline \multirow{2}{*}{ Perlakuan } & \multicolumn{5}{c}{ Indeks dominansi (Simpson) \pm SD } \\
\cline { 2 - 6 } & $5 \mathrm{MST}$ & $6 \mathrm{MST}$ & $7 \mathrm{MST}$ & $8 \mathrm{MST}$ & $9 \mathrm{MST}$ \\
\hline Kubis monokultur & $0,24 \pm 0,11$ & $0,46 \pm 0,17$ & $0,36 \pm 0,19$ & $0,23 \pm 0,12$ & $0,45 \pm 0,22$ \\
Kubis + tomat & $0,20 \pm 0,70$ & $0,41 \pm 0,47$ & $0,40 \pm 0,37$ & $0,34 \pm 0,23$ & $0,48 \pm 0,40$ \\
Kubis + Ageratum sp. & $0,18 \pm 0,28$ & $0,23 \pm 0,16$ & $0,42 \pm 0,20$ & $0,38 \pm 0,46$ & $0,49 \pm 0,34$ \\
& & \multicolumn{5}{c}{ Kriteria aplikasi insektisida } & \\
Ambang ekonomi & $0,21 \pm 0,26$ & $0,31 \pm 0,27$ & $0,35 \pm 0,13$ & $0,30 \pm 0,10$ & $0,44 \pm 0,91$ \\
Berjadwal & $0,29 \pm 0,14$ & $0,37 \pm 0,12$ & $0,83 \pm 0,51$ & $0,41 \pm 0,29$ & $0,48 \pm 0,36$ \\
Tanpa aplikasi & $0,80 \pm 0,33$ & $0,28 \pm 0,43$ & $0,24 \pm 0,15$ & $0,29 \pm 0,17$ & $0,39 \pm 0,17$ \\
\hline P-value A*B & 0,24 & 0,46 & 0,08 & 0,12 & 0,34 \\
\hline SD: & \multicolumn{5}{c}{ Polanaman } \\
\hline
\end{tabular}

SD: standar deviasi; MST: minggu setelah tanam.

Tabel 3. Komposisi arthropoda yang dikoleksi pada pitfall trap berdasarkan peranannya pada pertanaman kubis

\begin{tabular}{lcccc}
\hline \multirow{2}{*}{ Perlakuan } & \multicolumn{4}{c}{ Persentase (\%) \pm SD } \\
\cline { 2 - 5 } & Predator & Hama & Parasitoid & Saprofag \\
\hline \multirow{4}{*}{ Kubis monokultur } & $13,3 \pm 6,02$ & $6,7 \pm 2,26$ & $1,0 \pm 0,42$ & $79,0 \pm 40,9$ \\
Kubis + tomat & $14,7 \pm 8,35$ & $8,3 \pm 3,17$ & $2,0 \pm 0,90$ & $75,0 \pm 33,6$ \\
Kubis + Ageratum sp. & $23,3 \pm 7,11$ & $13,0 \pm 7,10$ & $3,0 \pm 1,15$ & $60,7 \pm 27,0$ \\
& & Kriteria aplikasi insektisida \\
Ambang ekonomi & $15,3 \pm 7,44$ & $9,7 \pm 6,9$ & $2,3 \pm 1,92$ & $72,7 \pm 26,1$ \\
Berjadwal & $17,0 \pm 2,18$ & $9,3 \pm 3,12$ & $1,0 \pm 0,16$ & $72,7 \pm 61,5$ \\
Tanpa aplikasi & $19,0 \pm 11,2$ & $9,0 \pm 2,99$ & $2,7 \pm 0,98$ & $69,3 \pm 33,6$ \\
\hline P-value A*B & 1,74 & 1,46 & 1,17 & 1,03 \\
\hline
\end{tabular}

SD: standar deviasi. 
pengaruh buruk terhadap kelimpahan serangga predator dan parasitoid.

Jumlah individu arthropoda tanah yang dikoleksi pada pitfall trap pada pola tanam dan kriteria aplikasi insektisida yang berbeda

Secara keseluruhan jumlah arthropoda tanah yang diperoleh, yakni terdiri atas 8 ordo, 18 famili, dan 21 spesies yang teridentifikasi (Tabel 4). Arthropoda yang aktif pada permukaan tanah yang kelimpahannya tertinggi ialah Famili Formicidae, Lycosidae, Isotomidae, dan Megalothorax yang berasal dari golongan predator dan pengurai. Terdapat 14 famili lain yang aktif di permukaan tanah, namun jumlah individu yang terperangkap pitfall trap masih tergolong rendah. Rendahnya populasi arthropoda pada ekosistem kubis dapat disebabkan oleh pengaruh aplikasi insektisida berjadwal maupun berdasar ambang ekonomi. Hal tersebut menunjukkan bahwa insektisida sintetik dapat mempengaruhi jumlah populasi arthropoda yang aktif di permukaan tanah. Penurunan populasi arthropoda permukaan tanah yang diaplikasi insektisida sintetik diduga akibat dari kerentanan arthropoda terhadap senyawa kimia tersebut.

Secara umum, arthropoda tanah yang ditemukan pada petak aplikasi insektisida (berjadwal dan berdasar ambang ekonomi) serta petak kubis monokultur menunjukkan jumlah arthropoda yang cenderung lebih rendah dibandingkan dengan petak kubis polikultur dan tanpa aplikasi insektisida.

Populasi predator dari Famili Formicidae yang ditemukan pada pitfall trap cenderung lebih tinggi pada pola tanam kubis + Ageratum sp., kubis + tomat, dan tanpa aplikasi insektisida (Tabel 4). Pengaruh tanaman Ageratum sp. mampu menarik beberapa predator untuk datang dan membuat koloni, seperti predator semut Formica sp. Predator ini memanfaatkan tanaman Ageratum sp. yang mampu menghasilkan nektar sebagai sumber makanan alternatif. Tanaman Ageratum sp. juga dapat menjadi tempat berlindung bagi Formica sp.

\section{PEMBAHASAN}

Keanekaragaman pada ketiga lahan tergolong sedang karena adanya campur tangan manusia dalam pengelolaannya dan menunjukkan perbedaan dengan keanekaragaman pada ekosistem yang masih alami. Rohman (2008) menyatakan bahwa lahan pertanian merupakan ekosistem yang secara fisik terkendali atau lebih banyak dikelola manusia sehingga komunitas penyusunnya juga bergantung pada pola atau praktik pertanian. Kegiatan pertanian menjadi penyebab menurunnya keanekaragaman biota dan fungsi ekosistem lahan karena adanya perubahan jenis dan kerapatan tumbuhan yang ditanam. Jika tingkat keanekaragaman suatu komunitas termasuk tinggi maka komponen biota lebih kompleks sehingga jaring-jaring serta rantai makanan lebih kompleks pula.

Pengaruh tanaman tumpang sari kubis dengan tomat dan penggunaan kubis dengan Ageratum sp. dapat memberikan keanekaragaman jenis atau vegetasi tanaman dalam satu areal pertanaman. Keragaman tanaman dapat meningkatkan populasi arthropoda tanah. Tobing (2009) menyatakan keanekaragaman yang terjadi dalam ekosistem baik karagaman tanaman serta keragaman arthropoda tanah akan membentuk interaksi internal dalam meningkatkan stabilitas serangga dalam perannya masing-masing dan membentuk tingkat tropik secara alami.

Pengaruh aplikasi insektisida dapat menyebabkan serangga mati. Penggunaan insektisida sintetik pada lahan pertanian dapat mempengaruhi keragaman populasi hama, predator, parasitoid dan pengurai. Winasa \& Rauf (2005) menyatakan bahwa indeks keanekaragaman spesies rendah pada petak yang diaplikasikan insektisida sintetik disebabkan oleh pengaruh bahan kimia insektisida dapat menyebabkan menurunnya sebaran jumlah individu dalam spesies sehingga penurunan sebaran individu mengakibatkan terjadinya penurunan nilai indeks keanekaragaman.

Nilai keanekaragaman serangga pada pola tanam kubis memiliki pengaruh timbal balik terhadap nilai dominansi. Semakin rendah nilai keanekaragaman, nilai dominansi akan lebih tinggi. Aplikasi insektisida berjadwal akan mempengaruhi kehidupan arthropoda tanah dan meningkatkan nilai dominansi serangga tertentu. Pada petak pertanaman berjadwal serangga yang umumnya banyak ditemukan, yakni serangga herbivor, seperti anjing tanah (Gryllotalpa) dan 
Tabel 4. Jumlah individu arthropoda tanah yang dikoleksi pada pitfall trap

\begin{tabular}{|c|c|c|c|c|c|c|c|}
\hline \multirow{2}{*}{$\begin{array}{l}\text { Ordo } \\
\text { Famili }\end{array}$} & \multirow{2}{*}{ Spesies } & \multicolumn{3}{|c|}{ Pola pertanaman } & \multicolumn{3}{|c|}{ Kriteria aplikasi insektis } \\
\hline & & KM & $\mathrm{KT}$ & $\mathrm{KA}$ & $\mathrm{AE}$ & JDWL & \\
\hline \multicolumn{8}{|l|}{ Araneae } \\
\hline Lycosidae & Lycosa pseudoannulata & 31 & 55 & 76 & 47 & 32 & \\
\hline Oxyopidae & Oxyopes & 20 & 24 & 23 & 23 & 18 & 2 \\
\hline \multicolumn{8}{|l|}{ Hymenoptera } \\
\hline \multirow[t]{2}{*}{ Ichneumonidae } & Diadegma semiclausum & 6 & 4 & 6 & 3 & 4 & \\
\hline & Inareolata sp. & 7 & 15 & 12 & 9 & 14 & 1 \\
\hline Formicidae & Formica sp. & 135 & 163 & 194 & 144 & 126 & 15 \\
\hline Braconidae & Cotesia & 5 & 2 & 5 & 4 & 1 & \\
\hline Eulophidae & Oomyzus sokolowskii & 2 & 2 & 4 & 2 & 1 & \\
\hline
\end{tabular}

Coleoptera

$\begin{array}{llrrrrrr}\text { Staphylinidae } & \text { Paederus fuscipes } & 9 & 12 & 15 & 11 & 9 & 9 \\ \text { Chrysomelidae } & \text { P. striolata } & 25 & 24 & 28 & 21 & 21 & 19 \\ \text { Coccinellidae } & \text { Coccinella } & 3 & 7 & 15 & - & 2 & 6\end{array}$

Orthoptera

\begin{tabular}{|c|c|c|c|c|c|c|}
\hline Gryllidae & Gryllus assimilis & 18 & 20 & 26 & 25 & 16 \\
\hline Acrididae & Acrididae sp. 1 & 2 & 4 & 2 & 3 & 3 \\
\hline Gryllotalpidae & Gryllotalpa hirsuta & 48 & 57 & 52 & 44 & 41 \\
\hline
\end{tabular}

Hemiptera

Reduviidae

Sycanus dichotomus

4

$9 \quad 15 \quad 7 \quad 6$

Diptera

$\begin{array}{llrrrrrr}\text { Drosophilidae } & \text { Drosophila melanogaster } & 1 & 5 & 4 & 5 & 2 & 2 \\ \text { Agromyzidae } & \text { Lyriomyza huidobrensis } & 7 & 15 & 12 & 17 & 10 & 15\end{array}$

Lepidoptera

Noctuidae

Chrysodeixis chalcites
Spodoptera litura
Agrotis ipsilon

$\begin{array}{rrrrrr}9 & 14 & 11 & 10 & 13 & 15 \\ 3 & 5 & 2 & 4 & 6 & 3 \\ 9 & 11 & 7 & 13 & 11 & 15\end{array}$

Colembolla

$\begin{array}{llrlllll}\text { Isotomidae } & \text { Collembola } \text { sp. 1 } & 924 & 1.107 & 1.162 & 1.002 & 993 & 1.148 \\ \text { Megalothorax } & \text { Ptenothrix atra } & 1.277 & 1.452 & 1.687 & 1.419 & 1.321 & 1.526\end{array}$

KM: kubis monokultur; KT: kubis dengan tomat; KA: kubis dengan Ageratum sp., AE: ambang ekonomi; JDWL: aplikasi berjadwal; TA: tanpa aplikasi.

ulat jengkal (Chrysodeixis chalcites (Esper)), dan beberapa serangga predator, seperti semut (Formica sp.), dan pengurai (Collembola). Tetrasani (2012) mengemukakan bahwa dalam komunitas yang keanekaragamannya tinggi maka suatu jenis tidak akan bisa dominan dan sebaliknya dalam komunitas yang keanekaragamannya rendah maka satu atau dua jenis akan menjadi dominan.

Keberadaan tanaman Ageratum sp. diindikasikan mampu menarik beberapa predator untuk datang dan membuat koloni, seperti predator semut Formica sp. Predator ini memanfaatkan 
tanaman Ageratum sp. yang mampu menghasilkan nektar sebagai makanan alternatif.

Tingginya populasi predator dan parasitoid yang ditemukan pada pola tanam kubis + Ageratum sp. diindikasikan kehadiran tanaman Ageratum sp. dapat menarik musuh alami untuk datang. Thamrin et al. (2017) menyatakan bahwa terdapat beberapa jenis gulma yang bermanfaat bagi parasitoid dan predator. Gulma dapat digunakan sebagai tempat berlindung, tempat bertelur, dan sumber pakan tambahan bagi predator dewasa. Musuh alami khususnya jenis predator mempunyai inang alternatif tertentu, yang selain menyerang inang atau mangsanya, jenis predator tersebut mempunyai tempat tinggal dan berlindung atau habitat yang disenanginya. Serangga jenis predator biasanya makan atau pengisap bunga dari gulma.

Populasi predator yang banyak ditemukan pada pitfall trap didominasi oleh serangga tanah dan serangga yang habitatnya di tajuk tanaman. Predator tanah tersebut di antaranya dari spesies Oecophylla smaradigna Fabricius, Sycanus dichotomus Stal, Formica sp., sedangkan kelompok predator yang umumnya berada di tajuk tanaman, seperti Lycosa pseudoannulata Boes. et Str., dan Oxyopes yang merupakan kelompok predator generalis dan biasanya memasang jaringjaring pada tajuk tanaman guna memerangkap mangsanya, namun terkadang predator ini juga dapat bergerak memburu mangsa di permukaan tanah. Predator lain yang ditemukan pada pitfall trap, yakni predator generalis Paederus fuscipes Curtis. Serangga ini bersifat kosmopolit (berada dimana-mana) dan berhabitat di tanah yang lembab.

Jenis parasitoid yang terperangkap, yakni Diadegma semiclausum Hellen, Eriborus argenteopilosus (Cameron), Oomyzus sokolowskii (Kurdjumov), dan Cotesia. Parasitoid D. semiclausum, $O$. sokolowskii, dan Cotesia merupakan parasitoid spesifik yang memarasit hama utama kubis $P$. xylostella, sedangkan parasitoid E. argenteopilosus merupakan parasitoid hama Crocidolomia pavonana Zell. Parasitoid umumnya ditemukan dalam jumlah sedikit pada pitfall trap karena aktivitas serangga ini umumnya terbang bebas dalam mencari inang.

Pengaruh buruk sebagai akibat langsung atau tidak langsung dari aplikasi insektisida umumnya merupakan ciri yang melekat pada insektisida karena adanya kesamaan fisiologi antara hama sasaran dengan predator dan parasitoid yang merupakan serangga bukan sasaran. Insektisida juga dapat berpengaruh secara tidak langsung terhadap musuh alami sebagai akibat berkurangnya ketersediaan mangsa atau inangnya, atau karena memangsa atau memarasit serangga hama yang terkontaminasi insektisida.

Pola tanam polikultur menambah keragaman tanaman sehingga penutupan tajuk akan lebih besar jika dibandingkan dengan lahan monokultur. Dari segi pengendalian hama, sistem polikultur sangat menguntungkan karena keragaman dan populasi musuh alami (parasitoid dan predator) juga relatif tinggi (Nurindah \& Sunarto 2008).

Predator generalis lain yang juga cukup mendominasi, yakni dari Ordo Araneae seperti Lycosa pseudoannulata dan Oxyopes. Namun, kehadiran predator ini kemudian menurun setelah dilakukan aplikasi insektisida secara berjadwal. Tubuhnya yang lunak dan peka terhadap insektisida sintetik serta cara hidupnya yang aktif di permukaan tanah menyebabkan arthropoda tersebut mudah terpapar insektisida sintetik (Winasa \& Rauf 2005). Beberapa penelitian menyebutkan bahwa predator laba-laba sensitif terhadap penggunaan insektisida. Insektisida dapat membunuh mangsa dari laba-laba sekaligus merubah perilaku labalaba sebagai predator dalam ekosistem.

Populasi Collembola cenderung lebih tinggi pada pola tanam kubis + Ageratum sp., kubis + tomat, dan tanpa aplikasi insektisida. Keragaman vegetasi tanaman dapat meningkatkan kelembaban tanah dan serasah serta bahan organik tanah dari daun-daun tanaman yang jatuh ke permukaan tanah. Yulmiharti (2003) menyebutkan bahwa materi organik merupakan faktor penting untuk kehidupan Collembola, sedangkan dampak tanpa aplikasi insektisida dapat meningkatkan jumlah sebaran Collembola.

Kehadiran Collembola dalam ekosistem secara tidak langsung dapat memberikan pengaruh besar terhadap struktur ekosistem. Collembola berperan sebagai pemangsa bagi kelompok Diatomae dan Nematoda. Collembola juga berperan dalam siklus makanan sebagai perombak bahan organik atau detritivor. Pada sebagian besar populasi Collembola tertentu pemakanan mikoriza akar dapat merangsang pertumbuhan simbion dan meningkatkan petumbuhan tanaman. Di lahan pertanian dapat menekan serangan patogen. 
Penelitian Shiraishi \& Enami (2003) menunjukkan bahwa adanya kemampuan Folsomia dalam menurunkan populasi jamur.

Keanekaragaman serangga dan tumbuhan dalam suatu pertanaman dapat memberikan pengaruh terhadap stabilitas ekosistem dengan membentuk interaksi jaring-jaring makanan. Interaksi mencakup hubungan mutualisme maupun kompetisi. Hubungan tersebut dapat memberikan kontribusi positif bagi terbentuknya stabilitas ekosistem (Tetrasani 2012).

\section{KESIMPULAN}

Secara umum perbedaan pola tanam dan kriteria aplikasi insektisida menunjukkan pengaruh terhadap keanekaragaman arthropoda tanah. Keanekaragaman arthropoda tanah cenderung lebih tinggi pada pola tanam kubis dan tanaman refugia dan tanpa perlakuan insektisida. Populasi arthropoda tanah paling tinggi yang diperoleh adalah Famili Formicidae, Lycosidae, Isotomidae, dan Megalothorax.

\section{DAFTAR PUSTAKA}

Arsanti ID, Sayekti AL, Kiloes AM. 2017. Analisis rantainilaikomoditaskubis (Brassicaoleracea $\mathrm{L}$ ): Studi kasus di Sentra Produksi Kabupaten Karo. Jurnal Hortikultura 27:269-278. doi: https:// doi.org/10.21082/jhort.v27n2.2017.p269-278.

Belz E, Koliker M, Balmi O. 2013. Olfactory attractiveness of flowering plants to the parasitoids Microplitis mediator: Potential implication for biological control. Journal BioControl 58:163-173. doi: https://doi. org/10.1007/s10526-012-9472-0.

BPS [Badan Pusat Statistik] 2015. Produksi Sayuran di Indonesia. Tersedia di: http://www.bps.go.id/. [diakses 15 September 2017].

Elhayati N, Agus M, Wibowo L, Fitriana Y. 2017. Keanekaragaman arthropoda permukaan tanah pada pertanaman ubikayu (Manihot utilissima Pohl.) setelah perlakuan olah tanah dan pengelolaan gulma. Jurnal Agrotek Tropika 3:158-164.

Nurindah, Sunarto DA. 2008. Konservasi musuh alami serangga hama sebagai kunci keberhasilan PHT Kapas. Jurnal Balai Penelitian Tanaman Tembakau dan Serat 7:1-11.
Helmi, Sulistyanto D, Purwatiningsih. 2015. Aplikasi agen pengendali hayati terhadap populasi hama (Plutella xylostella Linn. dan C. pavonana Zell.) dan musuh alaminya. Jurnal Ilmu Dasar 16:5562. doi: https://doi.org/10.19184/jid.v16i2.1352.

Rohman F. 2008. Struktur Komunitas Tumbuhan Liar dan Arthropoda sebagai Komponen Evaluasi Agroekosistem di Kebun Teh Wonosari Singosari Kabupaten Malang. Disertasi. Malang: Universitas Brawijaya.

Sastrosiswojo S, Uhan, Sutarya R. 2005. Penerapan Teknologi PHT pada Tanaman Kubis. Bandung: Balai Penelitian Tanaman Sayuran, Pusat Penelitian dan Pengembangan Hortikultura. Badan Penelitian dan Pengembangan Pertanian.

Setiawati. 2015. Pengaruh insektisida karbofuran terhadap kerusakan dan kehilangan hasil kentang akibat serangan Gryllotalpa hirsuta Burmeister (Orthoptera: Gryllotalpidae) serta dampaknya terhadap keanekaragaman arthropoda tanah. Jurnal Hortikultura 25:54-62. doi: https://doi. org/10.21082/jhort.v25n1.2015.p56-62.

Shiraishi H, Enami Y. 2003. Folsomia hidakana (Collembola) preventa damping off desease in cabbage and Chinese cabbage by Rhizoctonia solani. Jurnal Pedobiologia 47:33-38. doi: https://doi.org/10.1078/0031-4056-00167.

Subhan, Setiawati W, Nurtika N. 2005. Pengaruh tumpang sari tomat dan kubis terhadap perkembangan hama dan hasil. Jurnal Hortikultura 15:22-28.

Thamrin M, Asikin S, Susanti MA. 2017. Budi daya padi di lahan rawa pasang surut dan pengaruhnya terhadap penggerek batang padi. Jurnal Litbang Pertanian 36:28-38. doi: https:// doi.org/10.21082/jp3.v36n1.2017.p28-38.

Tetrasani. 2012. Keanekaragaman Serangga pada Perkebunan Apel Semi Organik dan Anorganik Desa Poncokusumo Kabupaten Malang. Skripsi. Malang: UIN MAulana Malik Ibrahim.

Tobing MC. 2009. Keanekaragaman Hayati dan Pengelolaan Serangga Hama dalam Agroekosistem. Disertasi. Medan: Universitas Sumatera Utara.

Winasa IW, Rauf A. 2005. Pengaruh samping aplikasi deltametrin terhadap artropoda predator penghuni permukaan tanah di pertanaman kedelai. Jurnal Entomologi Indonesia 2:39-47. doi: https://doi.org/10.5994/jei.2.2.39.

Yulmiharti. 2003. Distribusi Vertikal Collembola di Hutan Larangan Rimbo Paramuan Desa Alam Panjang Kec. Kampar. Pekanbaru: Universitas Riau. 